\title{
The impact of the socio-economic status on the German receptive noun and verb vocabulary in simultaneous bilingual children with Russian and Turkish as heritage languages
}

Der Einfluss des sozioökonomischen Status auf den passiven Nomenund Verbwortschatz im Deutschen bei simultan bilingualen Kindern der Herkunftssprachen Russisch und Türkisch

\section{Maria Antonietta Osso}

Humboldt-Universität zu Berlin, Deutschland

\begin{abstract}
A growing body of evidence shows a positive relation between the language skills of a child and the socio-economic status (SES) of his/her parents. These studies have mainly been conducted in an American English monolingual context. The current paper addresses the question of whether SES has a comparable impact on the simultaneous bilingual language acquisition. In this study, noun and verb test scores of German simultaneous bilingual children with Turkish and Russian as heritage languages are related to the SES of their parents - to verify the existence and the nature of a common pattern. The results do not show common patterns across the two heritage language groups, suggesting the existence of other confounding factors.
\end{abstract}

\section{Introduction}

In the OECD countries, children with immigration background or from socioeconomically disadvantaged families are found to underachieve in reading and math tasks compared to children without immigration background or from more advantaged families (OECD 2013). On the other hand, a study which monitors first-graders in Berlin also showed that the majority of first-graders with immigration background who do not possess sufficient German knowledge comes from unprivileged families (Oberwöhrmann and Bettge 2013).

In 2012, 12.1\% of all Berliner first-graders came from families in which at least one parent was born in Eastern Europe - or possessed the citizenship of an Eastern European country at the time of data collection. Following the same 
scheme, $11.3 \%$ of them had a Turkish family background and $5.9 \%$ came from an Arabic context. In total, $39.2 \%$ of all first-graders had a non-German background - 27.7\% in 2007 (Oberwöhrmann and Bettge 2013, Oberwöhrmann and Bettge 2007). Arguably, a considerable percentage of these children are exposed to more than one language.

As the degree of knowledge of the societal language is a predictor of academic success (Hoff 2013), a deeper understanding of the impact of the family background on the early language skills of bilingual children appears to have a high social value, as this may help promoting social mobility. It also has theoretical relevance, as it may give researchers further insights in the factors playing a role in bilingual language acquisition. The present paper examines the relation between the socio-economic status (SES) and the vocabulary skills of simultaneous bilingual children in the verbal and nominal domains. Its goal is to verify whether the correlation between SES and language acquisition observed for monolinguals also exists in the simultaneous bilingual acquisition.

\subsection{Simultaneous bilingual children and their lexical abilities}

When compared with the total vocabulary of same-age monolinguals, bilingual children usually possess a smaller vocabulary in each of their languages (Bialystok et al. 2010, Klassert 2011). Bialystok et al. (2010) were able to confirm this in an extensive study which involved 1,738 English monolinguals and bilinguals with several heritage languages. Given the large amount of differentiated data, it seems reasonable to assume that the difference in vocabulary size between monolingual and bilingual children is a real feature of bilingualism rather than a sampling effect.

Similar results were found for German as a societal language (Klassert 2011), too, with the difference between monolingual and bilingual children decreasing, but not disappearing, as age increases.

The difference in vocabulary size of bilingual and monolingual children is expected and related to the essence of bilingualism. Bilingual children are not (necessarily) exposed to more input than a monolingual child, but to the same amount of input distributed on two languages (Hoff 2006, Klassert 2011). From a distributed input, a distributed vocabulary with two smaller language specific vocabularies arises - the total size of the conceptual lexicon not being in question.

In the monolingual acquisition of German, the typical acquisition sequence is NOUNS $>$ VERBS (Kauschke 2012, Klassert 2011), with the noun phase beginning between $1 ; 0$ and $1 ; 6$ and the verb phase following between $1 ; 6$ and 2;6. The noun vocabulary is therefore expected to be bigger than the verb vocabulary during the first three years and smaller from age 3;0 on (Kauschke 2012). 
Studies that explored the composition of the early bilingual vocabulary of German as a heritage language found both a noun (Karasu 1995) and a verb advantage (Klassert 2011). These contradictory results, however, might be explained by the study designs. The studies differ for heritage language (Turkish for the first one, Russian for the second one) and method of data elicitation (spontaneous speech and naming test respectively), so that their results might not be directly comparable (Klassert 2011).

\subsection{Socio-economic status (SES) and vocabulary skills}

One of the first linguistic studies on the relation between socio-econimic status (SES) and language skills of young children was published in the 90es (Hart and Risley 1995). Since then, extensive researches have been conducted on the topic, mainly focusing on monolingual speakers. The linguistic domains that have been found to be sensitive to SES are morphology, phonetic competence, literacy skills, syntax and vocabulary size (see Huttenlocher 2010 for an overview). The vocabulary size seems to be particularly sensitive to SES differences (Hart and Risley 1995, Arriaga et al. 1998, Huttenlocher 2010, Rowe 2008, Hoff 2003).

Hart and Risley (1995) recorded and analyzed conversations between children and their main caretaker in their home environment. The study quantified the difference between the HSES and LSES linguistic environment in 153,000 tokens per week $(215,000$ words in the HSES families, and only 62,000 in the LSES ones). Despite some methodological critiques (Nation, undated), their results constituted an important contribution to the field and opened the word gap debate. These early insights were then confirmed by later studies, which also found LSES children to underperform on linguistic measures compared to HSES children (Huttenlocher 2010, Rowe 2008, Hoff 2003).

Arriaga et al. (1998) based their study on vocabulary checklists and compared the scores on productive vocabulary of very-low-SES children with a control sample. The LSES children underperformed the control group in vocabulary size. The data they collected about the monolingual/bilingual status show that $30 \%$ of the LSES children grew up in a multilingual context, while only approximately $15 \%$ of the MSES children were not monolingual (Arriaga et al. 1998).

Huttenlocher et al. (2010) recorded child-directed speech in English monolingual families for 20 months (child's age 2;2 to 3;10), finding SES- related differences in vocabulary size at all ages.

In the German-speaking countries, the relation between SES and vocabulary skills is being explored within the ongoing INPUT study (see Czinglar et al. 2015 for the first results). The focus of the project is the receptive vocabulary of bilingual (Turkish and German speakers) and monolingual (German speakers) 
preschoolers in Vienna and the first results confirm that vocabulary size correlates to SES in monolinguals but not in bilinguals.

Czinglar et al. explain this outcome as arising from the inherent difference between monolingual and bilingual acquisition. While monolingual acquisition patterns are easier to identify, more factors co-shape the bilingual acquisition (Czinglar et al. 2015, Hoff 2006, Klassert 2011). SES may play a more important role in monolingual than in bilingual acquisition.

\subsection{Operationalization of SES}

Several methods may be used to operationalize SES. Czinglar et al. (2015) employ international reference catalogues of occupational and educational status and prioritize the educational background over the economic situation. They code professions and levels of education based on standard norms and, if the two levels do not match, they correct a lower professional status to the higher level of education (but not a higher level of education to a lower professional status). Their assumption is that the level of education prevails on the job status when it comes to computing SES. Oberwöhrmann and Bettge $(2013,2007)$ code degree, current occupation and (since 2013) professional training numerically. They categorize school-leaving diplomas and professional status on a numerical scale and sum the scores reached in the three categories by each parent to obtain the SES level of the family. Other studies use the number of attended school years and the income range (Huttenlocher et al. 2010, Rowe 2008, Arriaga et al. 1998), or the kind of education (college vs. high school) and the prestige of the current occupation (professional/managerial position vs. unskilled, semi-skilled or service position) (Hoff 2003) as a reference. The data is collected for both parents or, in most studies, for the main caretaker only.

\section{Hypothesis}

A kindergarten study on the impact of SES on the acquisition of German as a societal language by simultaneous bilingual and monolingual preschoolers does not find any significant correlation between SES and vocabulary size in bilingual children (Czinglar et al. 2015). The authors argue that this might be connected to inherent characters of the bilingual language acquisition, which is strongly influenced by aspects of the specific linguistic environment, such as the proportion and frequency of each language, the presence of mixed language in the input and cultural factors. The impact of these factors might be stronger than the impact of SES (Czinglar et al. 2015). 
In the present study, I examine the vocabulary size of simultaneous bilingual children in the verbal and nominal domain and relate it to the SES of their parents. The goal is to verify if and how SES interacts with the early vocabulary size of simultaneous bilingual children. The following outcomes are possible:

(1) HSES children of both language groups possess a bigger vocabulary than their LSES counterparts. SES modulates vocabulary size in bilinguals.

(2) For no group a correlation between SES and vocabulary size is found. SES does not correlate with vocabulary size in bilinguals.

(3) A correlation between SES and vocabulary size only exists for one heritage language group; no common pattern can be observed across language communities.

\section{Study design}

\subsection{Data collection}

The data presented in this paper were collected within the BIVEM project (see Gagarina et al. (2014) for the first results) using the Patholinguistische Diagnostik bei Sprachentwicklungsstörungen (PDSS, Kauschke and Siegmüller 2010), a diagnostic tool for specific language impairment (SLI) which allows to assess the size of the German vocabulary in young children.

The test consisted of a word-picture matching task with 2 sets of 20 trials and was designed to assess the lexical skills of preschoolers in the verbal and nominal domain. In each trial, three pictures of semantically related nouns (or verbs, respectively) were presented to the child - one of them was the trial target, while the other ones were distractors. The tester would then name the target object (or action) and ask the child to point at the corresponding picture. In each trial, 0 (wrong answer) or 1 (right answer) points were obtained, for a total raw score of 0 to 20 point per set.

The raw score was then converted into a standardized score (T-score) obtained by comparison with same-age monolinguals (monolingual normal range for typically developing children between 40 and 60 points $^{1}$ ) and into a percentage value (PR) indicating what percentage of same-age monolinguals had an equal or lower score.

1 The PDSS test is not standardized for bilingual children. Any reference to the PDSS standard range is only intended as a comparison measure and not as an SLI diagnosis. 


\subsection{Sample}

Out of the 156 children who participated to the BIVEM study, 41 children were selected for the present study according to the following criteria: (1) the test scores were fully available prior to beginning this study, (2) the information about education and occupational status of at least one parent were available prior to beginning this study, (3) the SON-R results for non-verbal intelligence were within the normal range, (4) the length of exposure to the societal language was equal or above 9 months and (5) the children were simultaneous bilinguals.

Following Ruberg (2013), I will only refer to simultaneous bilingualism in case of an age of onset $(\mathrm{AoO})$ before 2;0. If the home language is the heritage language only, the $\mathrm{AoO}$ will be set at the age of kindergarten entrance, as a nonregular (below $25 \%$ of the input) exposure to the societal language is considered to be qualitatively and quantitatively insufficient to trigger language acquisition (Hoff 2006). Accordingly, the length of exposure will equal the age of the child if the home languages of the child are both the heritage and the societal language, or the time since kindergarten entrance if the societal language is not spoken at home.

Table 1: Sample: Age, AoO and length of exposure in months.

\begin{tabular}{llll}
\hline & & Turkish & Russian \\
\hline Age & Median & 44 & 39 \\
& Min-Max & $32-49$ & $33-50$ \\
\hline \multirow{2}{*}{ Length of exposure } & Median & 16 & 11,5 \\
& Median & $0-23$ & $0-22$ \\
\hline & Min-Max & $9-47$ & 31 \\
\hline
\end{tabular}

\subsection{Socio-economic status}

The SES was operationalized by means of a modified version of Oberwöhrmann and Bettge's report method (2013). Occupation and educational background of both parents (or of one parent doubled, if complete data were only available for one parent) were numerically coded and summed up. Higher scores correlate with higher prestige. 
Table 2: Operationalization of SES.

\begin{tabular}{ccc}
\hline Educational background & Occupational status & Scores \\
\hline Less than high school graduation & Professional training not required & 1 \\
\hline High school graduated & Professional training required & 2 \\
\hline College graduated & Collage education required & 3 \\
\hline
\end{tabular}

Each language group was divided in two subgroups taking the median SES score (7 points) as a discriminant.

Table 3: Sample: heritage language and SES.

\begin{tabular}{cccc}
\hline & Turkish & Russian & Total \\
\hline HSES & 11 & 12 & 23 \\
\hline LSES & 10 & 8 & 18 \\
\hline Total & 21 & 20 & 41 \\
\hline
\end{tabular}

\section{$4 \quad$ Results}

The results of the noun vocabulary test are summarized in Table 4 .

Table 4: Median and min-max values of the PDSS test results for nouns.

\begin{tabular}{ccccc}
\hline & \multicolumn{3}{c}{ Nouns - T-scores } & \multicolumn{2}{c}{ Russian } \\
& HSES & LSES & HSES & LSES \\
\hline Median & 31.0 & 21.0 & 33.0 & 33.0 \\
\hline Min-Max & $18-51$ & $17-58$ & $18-68$ & $18-66$ \\
\hline
\end{tabular}

The min-max scores reflect the high variability within the sample: both high and low scores are found across all groups. No group average reached the monolingual standard range (40-60 points). This is in line with previous findings indicating that the early bilingual vocabulary in each of the two languages is smaller than the monolingual whole vocabulary.

Showing a typical monolingual behavior, the Turkish HSES children reached in average better results than the Turkish LSES ones. The Russian groups, however, reached similar average scores and similar ranges across SES levels. Both Turkish groups underperformed their Russian counterparts. 
The impact of the socio-economic status on the German receptive noun and verb vocabulary in simultaneous bilingual children with Russian and Turkish as heritage languages

Table 5: Median and min-max values of the PDSS test results for verbs.

\begin{tabular}{ccccc}
\hline & \multicolumn{3}{c}{ Verbs - T-scores } \\
& HSES & LSES & HSES & LSES \\
\hline Median & 48.0 & 33.5 & 43.5 & 47.5 \\
\hline Min-Max & $30-66$ & $12-62$ & $30-53$ & $39-58$ \\
\hline
\end{tabular}

The verb test scores also showed a high variability. Again, the Turkish mean scores and their ranges seem to correlate with SES in a typically monolingual fashion, with the HSES children reaching the monolingual standard range.The Russian children of both SES groups reached the monolingual standard range. Interestingly, though, the results of HSES children were in average lower than the results of LSES children. The HSES Turkish group achieved better results than the HSES Russian group, while the LSES Russian group overperformed the LSES Turkish children. On average, all groups achieved better scores in the verbal than in the nominal domain.

Figures 1 to 4 graphically show the individual results with the SES scores on a continuous scale. The SES level of each child is reported on the $\mathrm{X}$-axis, while the Y-axis shows the percentage of same-aged monolinguals who achieved the same or a lower score. A visual inspection confirms the presence of a high variance between both individual scores and group patterns.

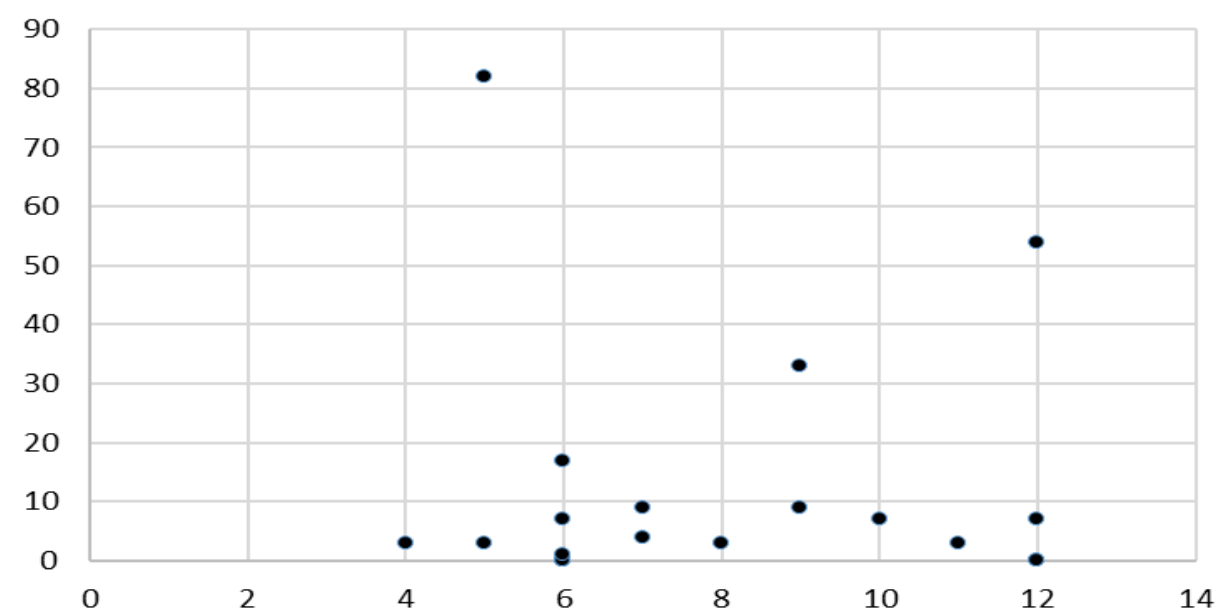

Figure 1: PR score of the noun test results for each SES level - Turkish group. 


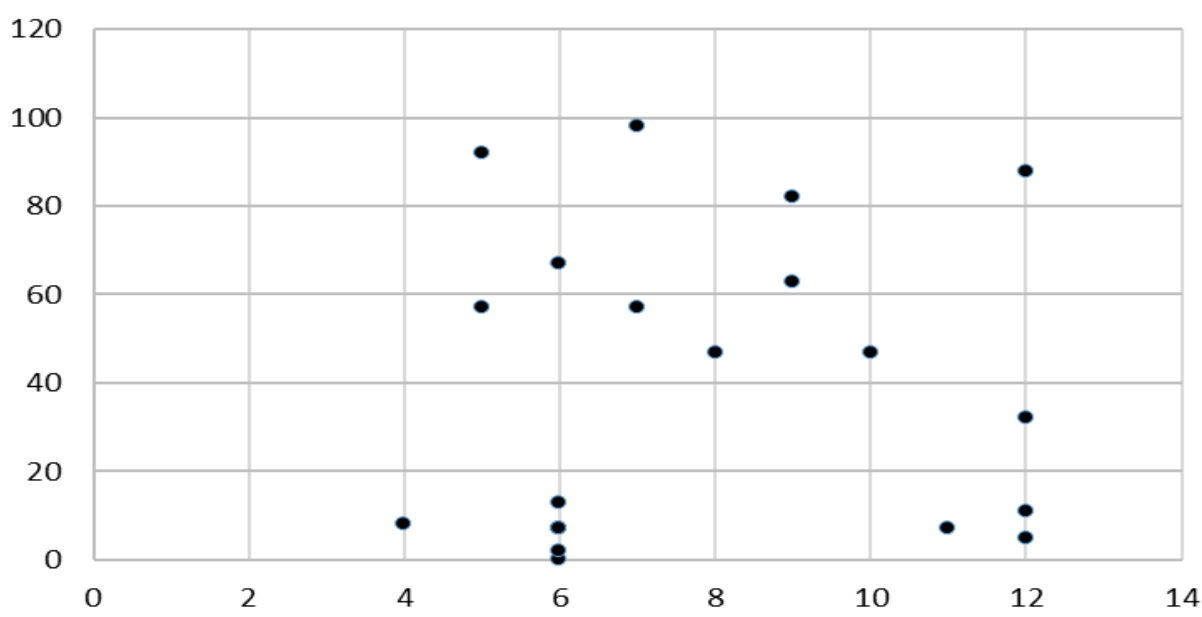

Figure 2: PR score of the verb test results for each SES level - Turkish group.

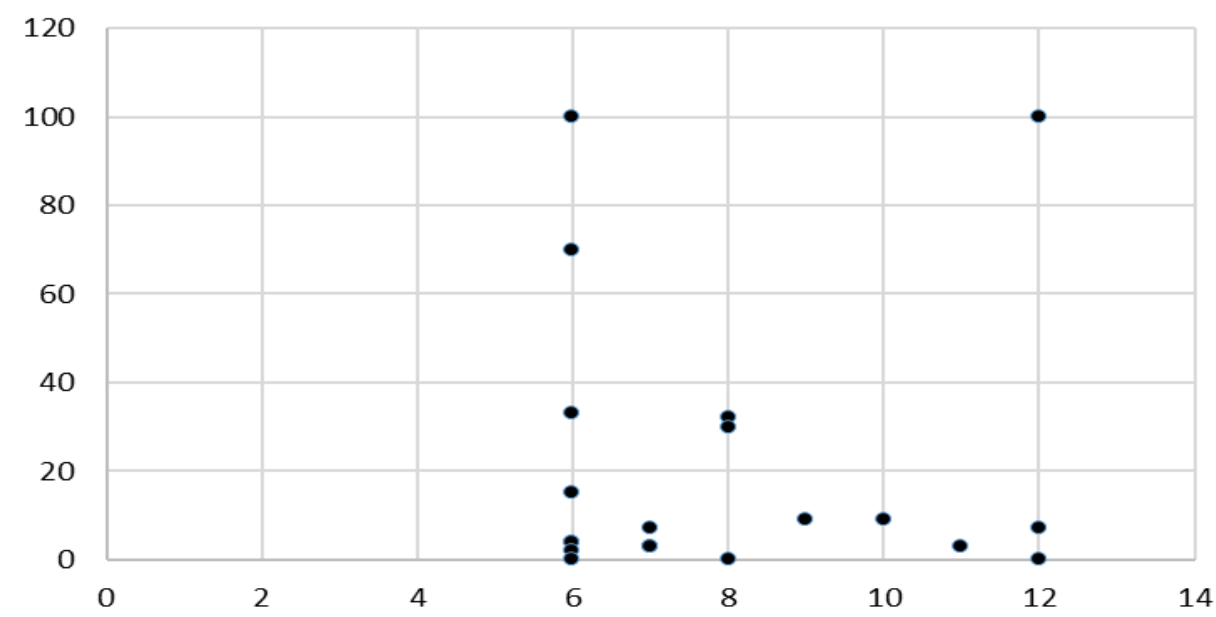

Figure 3: PR score of the noun test results for each SES level - Russian group.

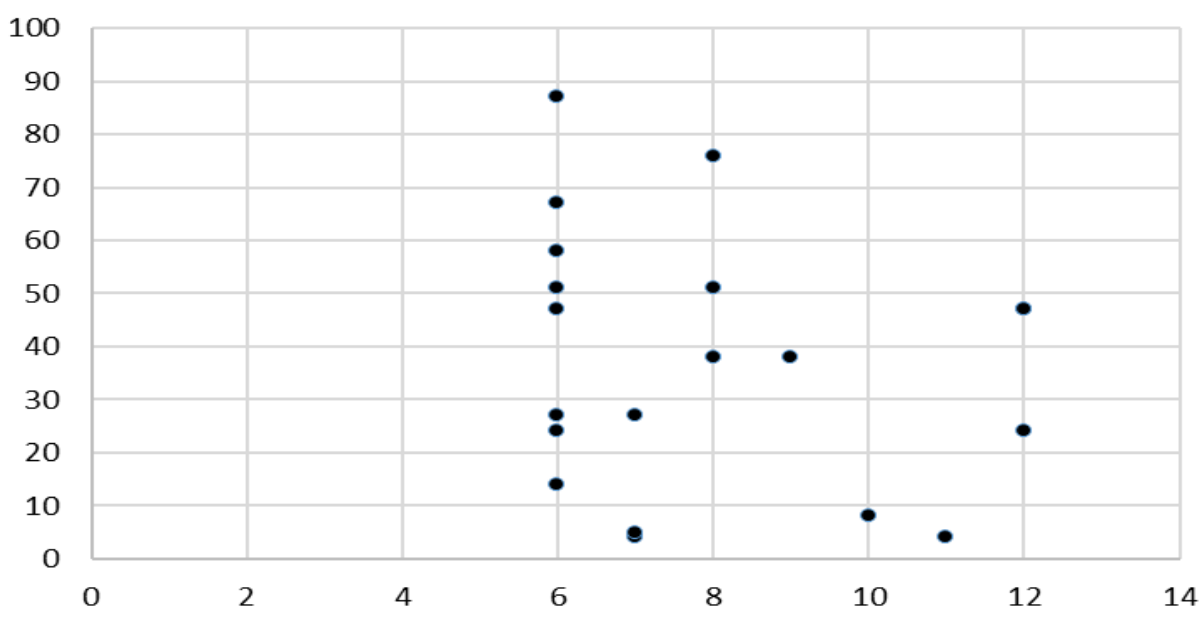

Figure 4: PR score of the verb test results for each SES level - Russian group.

\section{$5 \quad$ Discussion}


A visual inspection of the graphs as well as the absolute test scores suggest a high variability between individual children and no common pattern between the two language groups. Therefore, hypothesis (1) cannot be confirmed. Hypothesis (2) about the non-existence of a relation between SES and vocabulary size cannot be confirmed either, as a relation is found in the Turkish group.

In the noun test, the best score is achieved by a LSES child. This score can be probably seen as an outlier, as the second best LSES score is below the lowest HSES score.

The Russian groups show an unexpected pattern. While the noun vocabulary seems not to be influenced by SES, the median verb scores are higher for the LSES children than for the HSES group.

As different groups show a different degree of sensitivity to SES, hypothesis (3) can be confirmed. Unlike what one would expect in a monolingual sample, the acquisition of the societal language in bilingual children may be affected by SES to different degrees. As differences were found both between individual children and between language groups, it can be suggested that both individual and group differences modulate the effect of SES.

The individual differences can arise from the specific acquisition context of a single child, for example, the quantity and quality of input $\mathrm{s} /$ he is exposed to or the frequency of the visits to the heritage country. Group differences can arise from inherent structures of the societal language as well as from cultural characters of a specific language community.

Accordingly, the vocabulary skills of our Russian sample may be affected to a higher degree by variables other than SES that were not taken into consideration in the present study.

The integration strategy of a specific family or, more broadly, of a language community, has been found to have an impact on early language skills. The sociolinguistic study of Lambert and Taylor (1996) examined Cuban Spanish heritage speakers in Miami with results that resemble our Russian group's pattern. In rather disadvantaged families, Cuban American mothers encouraged and supported the acquisition of the societal language more than the maintenance of Spanish. In advantaged families, mothers preferred an additive integration strategy supporting the acquisition of the heritage language, too (Lambert and Taylor 1996).

Different integration strategies may have played a role in our sample, too, and have a stronger impact than SES within the same language community. In the HSES Russian sample, the children may be more supported than the LSES children in the acquisition of the heritage language, which leads to a quantitative disadvantage of the societal language and a slower acquisition of German during the earliest acquisition stages. 
The noun results were lower than the verb results for all groups. This result is consistent with previous findings (Klassert 2011), which, compared to the noun prevalence in monolingual children this age, show a verb advantage for bilingual children.

The SES data were collected via parent's questionnaires, which were distributed at the beginning of the project and were handed back to the researchers during the following three years. No data is available which precisely refers to the time of testing and it cannot be excluded that the occupational or education situation of the parents could have changed in the meantime.

The PDSS test takes a word sample as a measure of vocabulary size. This sample is controlled for word frequency and length and reliable for monolinguals - but might be controversial when used with bilingual children (Vogelbacher and Gawlitzek 2012), particularly because of the bilingual's tendency of using different languages for different purposes (Bialystok et al. 2010, Klasset 2011). To cope with this complexity, more tools and reference material specifically designed for simultaneous monolinguals are necessary.

The body of research on the impact of SES on language acquisition mainly comes from the USA and studies English as a societal language in combination with several heritage languages. As this relation may be modulated by cultural variables, further research involving different heritage and societal languages may be appropriate.

The inclusion of a monolingual control group as in Czinglar et al. (2015) may help testing the validity of the method as well as giving some comparative insights that are relevant for both theoretical and pedagogical reasons.

Effects arising from individual and group differences may be reduced by recruiting a broader sample and - ideally - by isolating and considering all further interacting variables.

\section{Summary}

While several studies confirm the existence of a relation between SES and vocabulary size in the monolingual acquisition, the impact of SES and the acquisition of German as a societal language has just recently begun to be explored. In the current study, no general pattern was found across the different heritage language groups. While in the Turkish group the HSES median scores for vocabulary were higher than the LSES children, the Russian children showed the exact opposite behavior. If SES has an impact on simultaneous bilingual acquisition, this effect may be modulated to varying degrees by other (individual and group) confounding variables. Further studies will need to explore and 
The impact of the socio-economic status on the German receptive noun and verb vocabulary in simultaneous bilingual children with Russian and Turkish as heritage languages

identify these variables in order to isolate the impact of SES on the early bilingual vocabulary.

\section{$7 \quad$ References}

Arriaga, Rose I., Fensona, Larry, Cronan, Terry \& Pethick, Stephen J. (1998): Scores on the MacArthur Communicative Development Inventory of children from low and middleincome families. Applied Psycholinguistics 19, 209-223.

Bialystok, Ellen, Luk, Gigi, Peets, Kathleen F. \& Yang, Sujin (2010): Receptive vocabulary differences in monolingual and bilingual children. Bilingualism: Language and Cognition 13(4), 525-531.

Czinglar, Christine, Korecky-Kröll, Katharina, Uzunkaya-Sharma, Kumru \& Dressler, Wolfgang U. (2015): Wie beeinflusst der sozioökonomische Status den Erwerb der Erstund Zweitsprache? Wortschatzerwerb und Geschwindigkeit im NP/DP-Erwerb bei Kindergartenkindern im Türkischen-Deutschen Kontrast. In: Köpcke, Klaus-Michael \& Ziegler, Arne (Eds.): Deutsche Grammatik in Kontakt. Deutsch als Zweitsprache in Schule und Unterricht. Berlin. 207-240.

Gagarina, Natalia, Posse, Dorothea, Düsterhöft, Stefanie, Topaj, Nathalie \& Acikgöz, Duygu (2014): Sprachförderung bei Mehrsprachigkeit: Erste Ergebnisse der BIVEM-Studie zur Wirksamkeit von Sprachförderung bei jüngeren mehrsprachigen Kindern. Eine Studie des Berliner Interdisziplinären Verbundes für Mehrsprachigkeit (BIVEM). Spektrum Patholinguistik 7, 109-118.

Hart, Betty, \& Risley, Todd R. (1995): Meaningful differences in the everyday experience of young American children. Baltimore. MD: Brooks.

Hoff, Erika (2003): The specificity of environmental influence: Socioeconomic status affects early vocabulary development via maternal speech. Child Development 74, 1368-1378.

Hoff, Erika (2006): How social context support and shape language development. Developmental review 26(1), 55-88.

Hoff, Erika (2013): Interpreting the early language trajectories of children from low-SES and language minority homes: implications for closing achievement gap. Developmental psychology 49(1), 4-14.

Huttenlocher, Janellen, Waterfall, Heidi, Vasilyeva, Marina, Vevea, Jack \& Hedges, Larry V. (2010): Sources of variability in children's language growth. Cognitive Psychology 61, $343-365$.

Karasu, Ibrahim (1995): Bilinguale Wortschatzentwicklung türkischer Migrantenkinder vom Vor- bis ins Grundschulalter in der Bundesrepublik Deutschland. Frankfurt am Main. (Werkstattreihe Deutsch als Fremdsprache 50).

Kauschke, Christina \& Siegmüller, Julia (2010): Patholinguistische Diagnostik bei Sprachentwicklungsstörung (PDSS). München. 
Kauschke, Christina (2012): Kindlicher Spracherwerb im Deutschen. Verläufe, Forschungsmethoden, Erklärungsansätze. Berlin. (Germanistische Arbeitshefte 45).

Klassert, Annegret (2011): Lexikalische Fähigkeiten bilingualer Kinder mit Migrationshintergrund. Eine Studie zum Benennen von Nomen und Verben im Russischen und Deutschen. Dissertation.

Lambert, Wallace E. \& Taylor, Donald M. (1996): Language in the lives of ethnic minorities: Cuban American families in Miami. Applied Linguistics 17 4, 477-500.

Nation, Paul (kein Datum): A brief critique of Hart, B. \& Risley, T. (1995) Meaningful differences in the everyday experience of young American children. Baltimore: Paul $\mathrm{H}$. Brooks Publishing.

Oberwöhrmann, Sylke \& Bettge, Susanne (2007): Gesundheitsberichterstattung. Spezialbericht 2007. Basisdaten zur gesundheitlichen und sozialen Lage von Kindern in Berlin. Senatsverwaltung für Gesundheit, Umwelt und Verbraucherschutz.

Oberwöhrmann, Sylke \& Bettge, Susanne (2013): Grundauswertung der Enschulungsdaten in Berlin 2012. Senatsverwaltung für Gesundheit und Soziales.

OECD (2013): PISA 2012 Results: Excellence Through Equity. Giving Every Student the Chance to Succeed (Volume II). OECD Publishing.

Rowe, Meredith (2008): Child-directed speech: relation to socioeconomic status, knowledge of child development and child vocabulary skill. Journal of Child Language 35, 185-205.

Ruberg, Tobias (2013): Problembereiche im kindlichen Zweitspracherwerb. Problematic domains in a child's second language acquisition. Sprache - Stimme - Gehör 37, 181185.

Vogelbacher, Markus \& Gawlitzek, Ira (2012): Zur objektiven Messung des Wortschatzerwerbs. In: Ahrenholz, Bernt \& Knapp, Werner (Eds.): Sprachstand erheben - Spracherwerb erforschen. Beiträge aus dem 6. Workshop „Kinder mit Migrationshintergrund". Freiburg. 53-72. 